\title{
MONITORAMENTO E GERENCIAMENTO DE BACIAS URBANAS ASSOCIADOS A INUNDAÇÃO: DIAGNOSE DA BACIA DO RIBEIRÃO QUILOMBO NA REGIÃO METROPOLITANA DE CAMPINAS UTILIZANDO GEOTECNOLOGIAS
}

\author{
Archimedes Perez Filho \\ Sérgio Henrique Vannucchi Leme de Mattos \\ Letícia Orsi \\ Andréa Koga Vicente \\ Luiz Eduardo Vicente ${ }^{1}$
}

\begin{abstract}
Resumo: As características sociais e ambientais de diversas cidades brasileiras, tais como a impermeabilização excessiva do solo e parcela considerável da população ocupando fundos de vales e áreas de inundação, acarretaram problemas crônicos de enchentes nos últimos anos. Tais problemas causaram grandes impactos em áreas urbanas, prejudicando as condições de vida da população e rovocando prejuízos econômicos. A área de estudo desse trabalho é a bacia do Ribeirão Quilombo, o qual é afluente do Rio Piracicaba e ocupa uma área de 39 mil hectares, abrangendo seis municípios da Região Metropolitana de Campinas (RMC), são eles: Campinas Sumaré, Hortolândia, Nova Odessa, Paulínia e Americana. A bacia do Quilombo constitui-se numa interface emblemática de problemas ambientais urbanos, envolvendo ocupações de áreas de risco ao longo dos anos, eventos extremos de precipitação, danos estruturais e perda de vidas. Uma constante em diversas outras áreas não só da RMC, como de outros grandes centros urbanos brasileiros. Esta área torna-se, portanto, o exemplo/piloto ideal de estudos cujo objetivo é o elenco de ações de ordem estrutural e não-estrutural, as quais possam nortear processos de planejamento e gestão. Este trabalho realiza uma diagnose dos elementos físicos e antrópicos da bacia do Ribeirão Quilombo em sua disposição espacial no decorrer de 1990 a 2000. Utilizando instrumentos de geotecnologias em um ambiente de Sistema de Informações Geográficas, dessa forma elaborou-se um banco de dados espacial o qual subsidiou análises e conclusões fundamentais para o entendimento da dinâmica ocupacional de áreas de risco em bacias urbanas. Pode-se constatar, por exemplo, que houve aumento da vulnerabilidade da população frente aos episódios de alagamento. Este fato se deu em decorrência da ocupação de áreas de risco e do aumento das precipitações intensas verificadas na região.
\end{abstract}

Palavras-chave: Inundação; Gerenciamento de riscos; Bacia hidrográfica urbana; Sistema de Informações Geográficas; Região Metropolitana de Campinas.

\section{Introdução}

As características sociais e ambientais de diversas cidades brasileiras, tais como a impermeabilização excessiva do solo e parcela considerável da população ocupando fundos de vale e áreas de inundação, acarretaram problemas crônicos de enchentes nos últimos anos, causando grandes impactos em áreas urbanas, prejudicando as condições de vida da população e provocando prejuízos econômicos.

O modelo de urbanização observado nas grandes cidades mundiais permite a ocupação das planícies de inundação dos cursos d'água urbanos e expõe a população ao risco de impactos de enchentes, agravados pelos episódios anômalos de precipitação. Em regiões tropicais, devido às características físico-naturais, as inundações e enchentes decorrentes de chuvas intensas são acidentes comuns.

Os eventos extremos fazem parte da dinâmica climática de um local, e tornam-se acidente quando "superam a capacidade material de uma determinada organização social para absorver, amortizar ou evitar seus efeitos negativos" (GONÇALVES, 2003).

Assim, uma das maiores dificuldades quanto à prevenção dos impactos pluviais reside no fato de que toda a estrutura urbana é "planejada" usando como parâmetro apenas o estado médio dos fenômenos meteorológicos, desconsiderando as anomalias que fazem parte do clima local, e que fatalmente ocorrem.

\footnotetext{
1 Departamento de Geografia, Instituto de Geociências, Universidade Estadual de Campinas (Unicamp). Rua Pandiá Calógeras, 51; CEP: 13084-970 Campinas-SP. e-mail: archi@ige.unicamp.br, sergiohm@ige.unicamp.br, leticiaorsi@yahoo.com, andreak@ige.unicamp.br, vicente@ige.unicamp.br
} 
Portanto, a chuva figura como 0 elemento deflagrador dos acidentes relacionados a inundações, mas a ocupação inadequada de áreas sujeitas a alagamentos é o principal componente da vulnerabilidade da população frente a esses eventos, e decorre de processos políticos, econômicos e culturais.

Tem-se observado o crescimento no número de pessoas afetadas nos anos mais recentes, mesmo durante eventos pluviais não tão extremos, devido ao aumento da vulnerabilidade da população.

Tradicionalmente, o gerenciamento de riscos associados a inundações é feito enfatizando-se a realização de medidas estruturais, tais como canalização e retificação dos corpos d'água. Apesar dos altos custos financeiros e tempo envolvidos em ações como estas, via de regra, elas se mostram defasadas e insuficientes para solucionar os problemas relacionados e, não raro, provocam sua intensificação.

Daí a importância da adoção de medidas não-estruturais como procedimento complementar no gerenciamento de riscos associados a inundações. A adoção destas medidas pode significar mudanças importantes no sistema de gestão de políticas públicas, concatenando diferentes setores da sociedade por intermédio de parcerias que integrem população, poder público, iniciativa privada e institutos de pesquisa, com o objetivo de encontrar soluções mais efetivas.

Como medida não-estrutural, destaca-se um sistema de monitoramento e alerta de inundações, o qual permitiria avaliar em tempo real a probabilidade de sua ocorrência, em determinada área. Este sistema poderia também auxiliar os órgãos competentes (Governo Estadual e Defesa Civil) a elaborar seus planos de ações para minimizar os riscos e prejuízos associados a inundações, evitando grande parte dos perigos de vida e transtornos que acometem freqüentemente a população atingida.

Entre os grandes entraves em pesquisas relacionadas a monitoramentos e mapeamentos no Brasil, encontra-se a falta de dados em escala adequada para estudos locais. Em pesquisas ambientais, as quais co-relacionam parâmetros físico-naturais com recortes diversos da ocupação antrópica, a situação torna-se mais grave. Fenômenos contínuos, como chuva, ventos e suas derivações não possuem um registro suficientemente refinado quando se trata de algumas áreas de estudo como, por exemplo, bacias hidrográficas urbanas.

Dessa maneira, a necessidade de previsão de eventos extremos de caráter dinâmico e complexo (inundações, alagamentos, cheias) esbarra na baixa resolução das malhas de registro dos sistemas de coleta de dados e na conseqüente escassez de metodologias aptas a este tipo de previsão. No espaço de poucos metros a grande variação do fenômeno pode comprometer sua compreensão, como no caso das chuvas, onde pode-se encontrar variações de até $20 \mathrm{~mm}$ em diferentes pontos de uma mesma bacia. A alta densidade populacional, própria de meios urbanos, também remete à necessidade de precisão cartográfica onde, na exigüidade espacial de habitações de pequeno porte, reside uma grande número de pessoas.

No que se refere ao estudo de bacias urbanas, trata-se portanto de criar condições para o monitoramento em alta resolução, gerando um ambiente de avaliação refinado, o qual pode ser utilizado como referência por diversas áreas, gerando dados, aprimorando modelos, engendrando e norteando políticas públicas de médio e longo prazo de maneira mais efetiva e precisa.

Dessa forma, a iniciativa de implantação de bacias urbanas monitoradas e voltadas para o estudo de eventos extremos num contexto pluvio-fluvial, assim como suas aplicações na gestão e planejamento urbano, é inédita no Brasil, o que a coloca como fundamental para o balizamento de demais estudos que se adeqüem à realidade físico-natural (geomorfológia, climática, pedológica) e social (o padrão de ocupações das cidades brasileiras).

Assim sendo, esta proposta de trabalho considera a bacia hidrográfica do Ribeirão Quilombo como área-piloto e objetiva sua caracterização física e socioeconômica, bem como a co-relação de variáveis através de Geotecnologias. A elaboração do banco de dados geográfico (SIG) destina-se a fase diagnose de processos concernentes à ocupação da região, constituindo-se como parte do projeto "Monitoramento e gerenciamento de bacias urbanas associados a inundação: projeto-piloto de implementação de Sistema de Alerta na bacia hidrográfica do Ribeirão Quilombo".

O Ribeirão Quilombo é afluente do Rio Piracicaba e integrante da Bacia do Piracicaba/Capivari/Jundiaí (Fig. 01). Além disso, situa-se na Unidade Hidrográfica de Gerenciamento de Recursos Hídricos do Estado de São Paulo (UGRHI-5), pertencente à Diretoria de Bacia do Médio Tietê (BMT), do Departamento de Águas e Energia Elétrica do Estado de São Paulo (DAEE-SP).

Esta bacia faz parte da rede de drenagem da Região Metropolitana de Campinas (RMC), situada em sua porção sudoeste abrangendo seis municípios: Sumaré, Americana, Nova Odessa, Campinas, Hortolândia e Paulíía.

A bacia situa-se em uma área de transição climática, onde atuam diferentes sistemas atmosféricos tropicais e extratropicais, 
o que resulta em uma grande complexidade de tipos de tempo, que são, portanto, de difícil previsão.

A natureza dessas chuvas dificulta a tomada de medidas para prevenção, absorção e minimização dos impactos associados, por ocorrerem de forma repentina. Dentre os estudos realizados sobre o clima local (TAVARES, 1971) identificou 0 sistema Frontal Polar como de participação importante na gênese das precipitações na região. Entre os episódios mais intensos ocorridos nos municípios da RMC, entre as décadas de $1960 \mathrm{e}$ 1990, a maior parte está associada à passagem de frentes frias no verão. Também sob o domínio do sistema Tropical Atlântico acontecem chuvas localizadas e de grande intensidade.

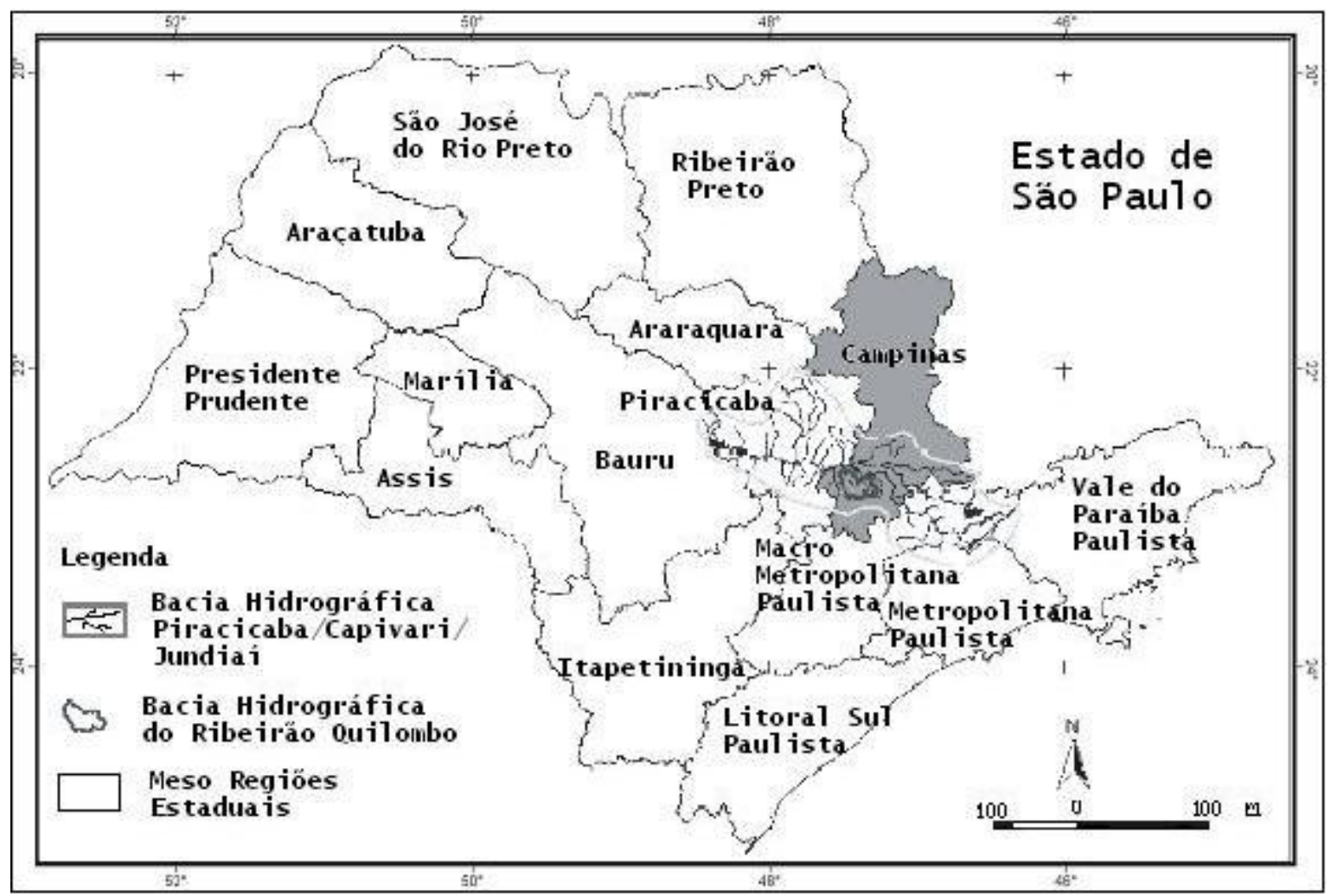

Figura 1 Localização da sub-bacia hidrográfica do Ribeirão Quilombo no Estado de São Paulo.

\section{Métodos e Técnicas}

A implantação de uma bacia hidrográfica urbana monitorada, voltada para o estudo de eventos extremos, depende inicialmente da determinação do conjunto de variáveis físicas e sociais que influenciem o fenômeno estudado. Em uma fase posterior, seria possível o desenvolvimento de um sistema de alerta eficiente, que pondere corretamente as variáveis em questão.

Torna-se evidente, portanto, que a fase de compreensão dos fatores atuantes em uma determinada área de estudo é elemento chave no desenvolvimento de tal sistema. Por conse- guinte, sua análise demanda um satisfatório arcabouço de dados, resultante de investigações em escala adequada.

A carta-base da bacia hidrográfica do Ribeirão Quilombo foi compilada a partir de cartas topográficas digitais na escala 1:50.000, disponibilizadas pelo Projeto Piracena (Esalq-USP). Este material possibilitou a delimitação da bacia (Fig. 2) e a criação do modelo digital do terreno (MDT) (Fig. 3), propiciando análises hipsométricas (declividade, altimetria), as quais guardam estreita correlação com eventos de inundação.

Com o objetivo de delimitar áreas com maior densidade habitacional, foram utilizadas imagens de satélite do 
sensor Landsat $7-\mathrm{ETM}^{+}$, órbitas ponto 219/76 e 220/76 do ano de 2000, tendo como base comparativa de análise do crescimento de áreas ocupadas (PIRES E SANTOS, 2002). Com base nos dados de setores censitários do Censo de 2000 (IBGE, 2002), avaliou-se a qualidade de vida da população residente nas áreas urbanas de Campinas situadas na Bacia do Quilombo.

Para tanto foram utilizados indicadores relativos ao grau de ocupação (densidade demográfica e de domicílios), às condições de moradia (domicílios improvisados e/ou localizados em favelas), ao saneamento ambiental (coleta de lixo e esgoto), à renda dos responsáveis por domicílio (inferior a 2 salários mínimos e superior a 10 salários mínimos) e escolaridade (pessoas maiores de 5 anos não-alfabetizadas e responsáveis por domicílio que freqüentaram curso superior). Nas análises, considerou-se apenas os setores censitários localizados em área urbanizada e que possuíam mais de $50 \%$ de sua área dentro da bacia do Quilombo. Os dados foram calculados tanto para cada setor censitário isoladamente quanto para o conjunto de setores. Desta forma, obteve-se um quadro geral da situação da população campineira residente na bacia do Quilombo bem como identificou-se as disparidades socioeconômicas aí existentes, coaduando-as com dados físicos.

\section{Resultados}

Com a elaboração da carta-base, pôde-se calcular a área da bacia, valor em torno de 39 mil hectares. O comprimento total dos cursos d'água mapeados nesta escala (1:50000) atinge aproximadamente 368 quilômetros. Somente o Ribeirão Quilombo possui cerca de 50 quilômetros desde sua nascente no município de Campinas, passando por Sumaré, Nova Odessa e Americana, até desembocar no Rio Piracicaba (Fig. 2).

Quanto ao relevo da bacia, pode-se notar na Fig. 3 que é pouco acidentado, com cotas de elevação predominantemente em torno de 600 metros. Esta característica (relevo pouco acidentado) requer, portanto, um novo modelo de elevação, formulado a partir de curvas de nível com eqüidistância de 5 metros. Dessa maneira, maiores detalhes (encobertos no modelo atual pela eqüidistância de 20 metros) poderão ser revelados, 0 que contribuirá para a ponderação deste fator na formulação de que contribuirá para a ponderação deste fator na formulação de um sistema de alerta de inundações mais eficiente (Fig. 3).

A bacia do Ribeirão Quilombo localiza-se na RMC (Fig. 4). Residiam nesta região cerca de 2,3 milhões de pessoas no ano de 2000, de acordo com o último censo do IBGE.

Dos 19 municípios da RMC, 6 deles estão parcial ou totalmente inseridos na bacia do Quilombo (Tab. 1).

Nas últimas décadas, a RMC apresentou grande desenvolvimento econômico, sendo que a atividade industrial e 0 setor tecnológico atraíram um significativo contingente populacional para seus municípios. Em conseqüência, a estrutura urbana foi se expandindo, nem sempre de forma adequada para absorver os extremos de precipitação.

Somente no período de 1991 a 2000, este crescimento populacional foi de $22,6 \%$ (Tab. 2).

Embora o maior crescimento absoluto da população tenha ocorrido em Campinas, os municípios do seu entorno apresentaram maior crescimento relativo, confirmando a tendência observada desde a década de 1970 para a RMC (Baeninger, 2001).

Hortolândia e Sumaré, municípios com grande área territorial inserida na bacia do Quilombo e/ou contribuição significativa na composição da bacia, registraram altos índices de crescimento populacional (Tab. 2). Foram também nestes municípios em que ocorreram os maiores acréscimos de áreas urbanizadas.

Tabela 1 Municípios situados na bacia do Quilombo

\begin{tabular}{lrrrr}
\hline \multicolumn{1}{c}{ Município } & Área total (ha) & $\begin{array}{r}\text { Área na } \\
\text { bacia (ha) }\end{array}$ & $\begin{array}{r}\text { Área na } \\
\text { bacia (\%) }\end{array}$ & $\begin{array}{r}\text { Composição } \\
\text { da bacia (\%) }\end{array}$ \\
\hline Americana & $13.368,8$ & $4.381,5$ & 32,8 & 11,3 \\
Campinas & $79.592,3$ & $7.177,1$ & 9,0 & 18,4 \\
Hortolândia & $6.225,3$ & $6.222,3$ & 100,0 & 16,0 \\
Nova Odessa & $7.332,2$ & $5.908,1$ & 80,6 & 15,2 \\
Paulínia & $13.938,7$ & $2.603,1$ & 18,7 & 6,7 \\
Sumaré & $15.311,9$ & $12.612,2$ & 82,4 & 32,4 \\
\hline Total & $135.769,2$ & $38.904,3$ & 28,7 & 100 \\
\hline
\end{tabular}

Fonte: IBGE/ SIG Bacia do Quilombo. 


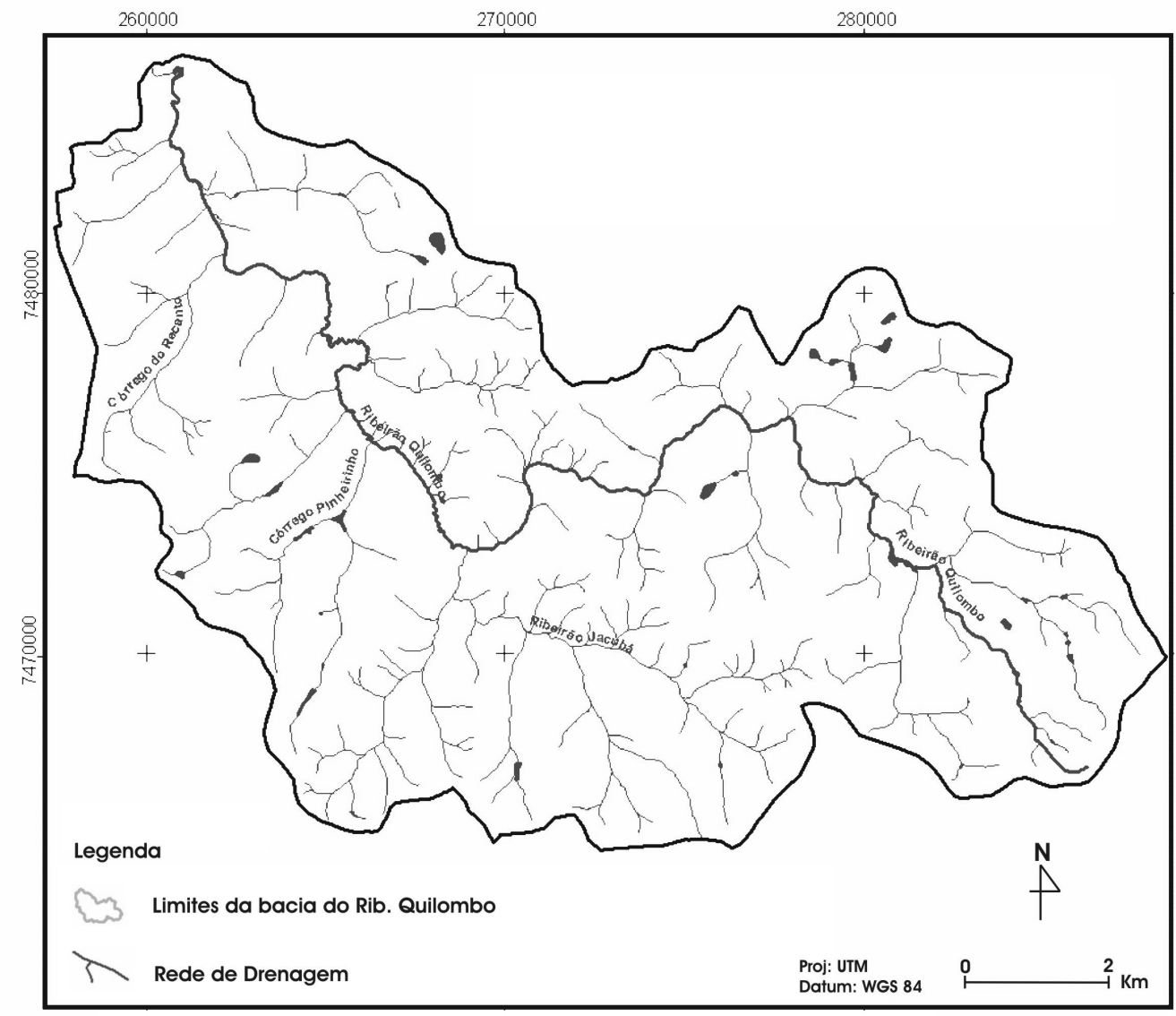

Figura 2 Delimitação da Bacia Hidrográfica do Ribeirão Quilombo. Fonte: Cartas topográficas em escala 1: 50000 (IBGE).

Tabela 2 Crescimento populacional nos municípios inseridos na bacia hidrográfica do Ribeirão Quilombo

\begin{tabular}{lrrrr}
\hline Município & $\begin{array}{r}\text { População em 1991 } \\
\text { (hab) }\end{array}$ & $\begin{array}{r}\text { População em 2000 } \\
\text { (hab) }\end{array}$ & Acréscimo (hab) & Acréscimo (\%) \\
\hline Americana & 153.779 & 182.084 & 28.305 & 18,4 \\
Campinas & 846.434 & 967.921 & 121.487 & 14,4 \\
Hortolândia & 85.859 & 151.669 & 65.810 & 76,6 \\
Nova Odessa & 34.063 & 42.066 & 8.003 & 23,5 \\
Paulínia & 36.706 & 51.242 & 14.536 & 39,6 \\
Sumaré & 141.011 & 196.055 & 55.044 & 39,0 \\
\hline Total & 1.297 .852 & 1.591 .037 & 293.185 & 22,6 \\
\hline
\end{tabular}

Fonte: IBGE - Censos Demográficos de 1991 e 2000 


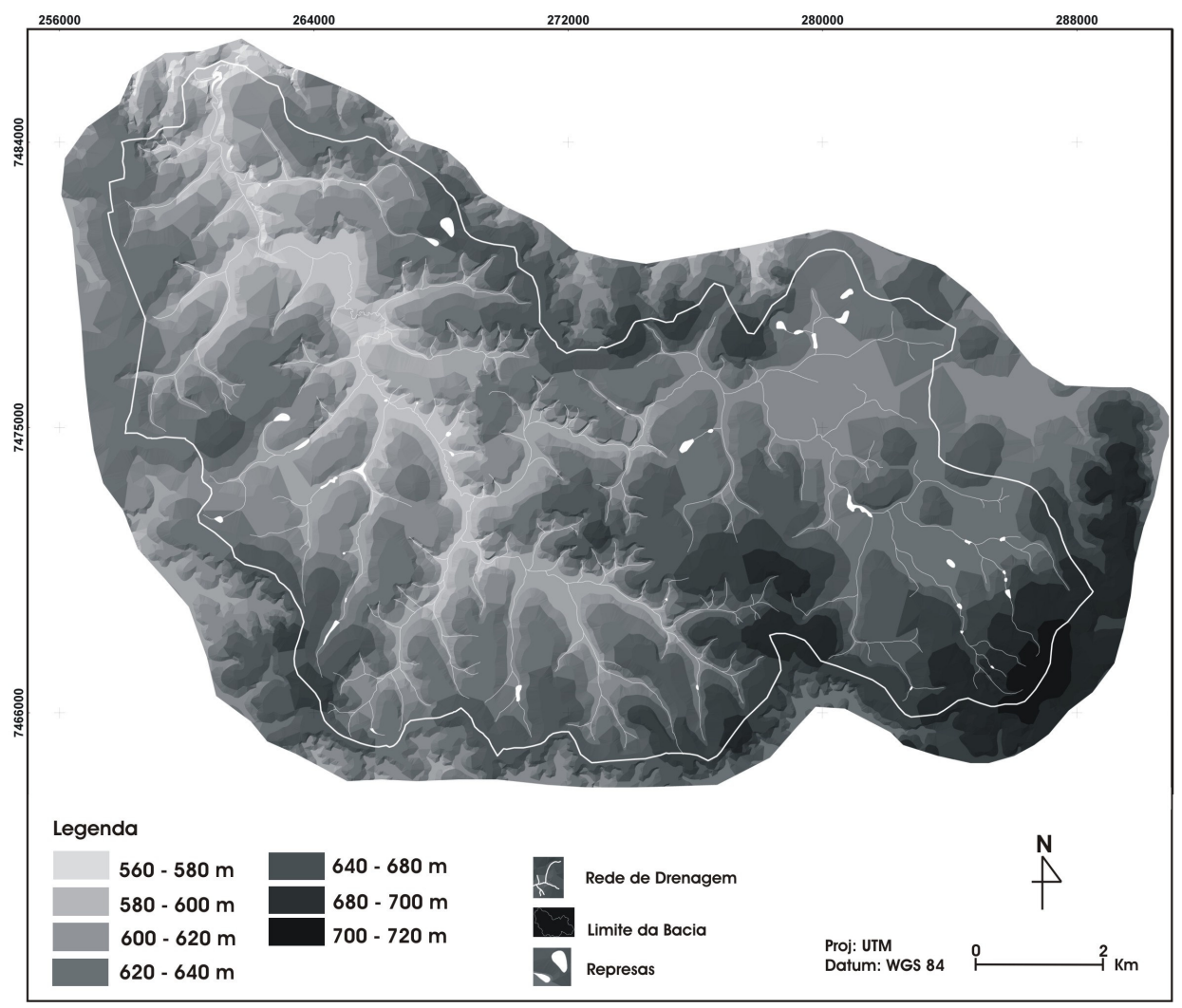

Figura 3 Relevo da Bacia Hidrográfica do Ribeirão Quilombo. Fonte: Cartas topográficas em escala 1: 50000, curvas de nível com eqüidistância de 20 metros (IBGE).

Tabela 3 Crescimento das áreas urbanizadas (ha) nos municípios inseridos na bacia hidrográfica do Ribeirão Quilombo

\begin{tabular}{lrrrr}
\hline Município & Área Urbanizada 1989 & Área Urbanizada 2000 & Acréscimo (ha) & Acréscimo (\%) \\
\hline Americana & $2.337,7$ & $2.533,9$ & 196,2 & 8,4 \\
Campinas & $2.397,8$ & $2.630,0$ & 232,2 & 9,7 \\
Hortolândia & $2.904,1$ & $3.567,2$ & 663,1 & 22,8 \\
Nova Odessa & 871,8 & 979,9 & 108,1 & 12,4 \\
Paulínia & 212,2 & 489,5 & 277,3 & 130,7 \\
Sumaré & $3.785,0$ & $4.237,0$ & 452,0 & 11,9 \\
\hline Total & $12.508,6$ & $14.437,5$ & $1.928,9$ & 15,4 \\
\hline
\end{tabular}

Fonte: Pires e Santos (2002) 


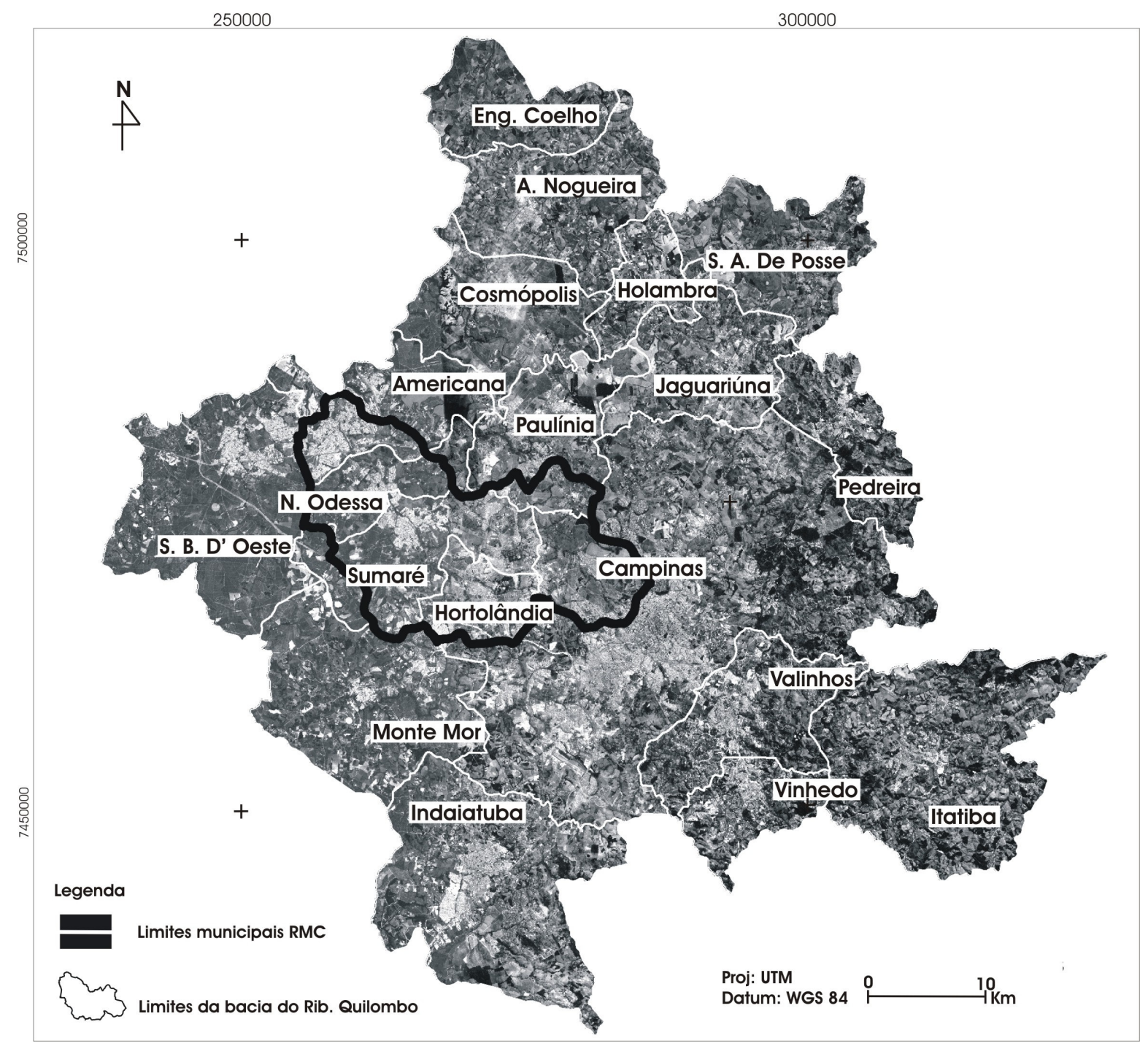

Figura 4 Localização da bacia do Quilombo na região metropolitana de Campinas - Landsat 7-ETM+/ CC 345.

Juntos, estes municípios aumentaram em novas áreas urbanizadas aproximadamente $1.115 \mathrm{ha}$, o equivalente a $57,8 \%$ do crescimento total verificado no período estudado (Fig. 5 e Tab. 3). Os dois municípios se configuraram historicamente como a periferia de Campinas, tendo como ônus desse processo uma infra-estrutura mais precária e, portanto, mais vulnerável. São áreas mais depreciadas, e sofrem de forma contundente os impactos, sejam eles relativos ao desenvolvimento (áreas de periferia) ou aos fenômenos ambientais (enchentes).
Este mesmo processo de vulnerabilidades diferenciadas observado em escala regional se repete dentro do município de Campinas. A parte urbanizada da bacia do Quilombo em Campinas abriga população em condições bastante discrepantes, apresentando desde bairros de classe média-alta até favelas, estas últimas se concentrando nos fundos de vales e áreas de inundação. Estes contrastes são atestados pelos dados derivados do Censo de 2000 para setores censitários (Tab. 4). 
$\mathrm{Na} \mathrm{RMC}$, diversos cursos d'água cortam os municípios, e são constantes os danos causados pelas inundações e enchentes Quilombo, em especial, atingem seis municípios da RMC. Os impactos relacionados a esses alagamentos estão, em sua maioria, associados aos episódios de chuvas intensas, que combinam um grande volume de precipitação em um curto espaço de tempo, e são oriundos das enchentes resultantes do abundante escoamento superficial potencializado pelo alto nível de impermeabilização do solo, e posterior transbordamento dos cursos d'água.

A ocorrência destes aguaceiros segue o ritmo sazonal, incidindo na primavera e principalmente no verão, quando os altos valores de temperatura e umidade favorecem a atividade convectiva e, conseqüentemente, a gênese de precipitações intensas.

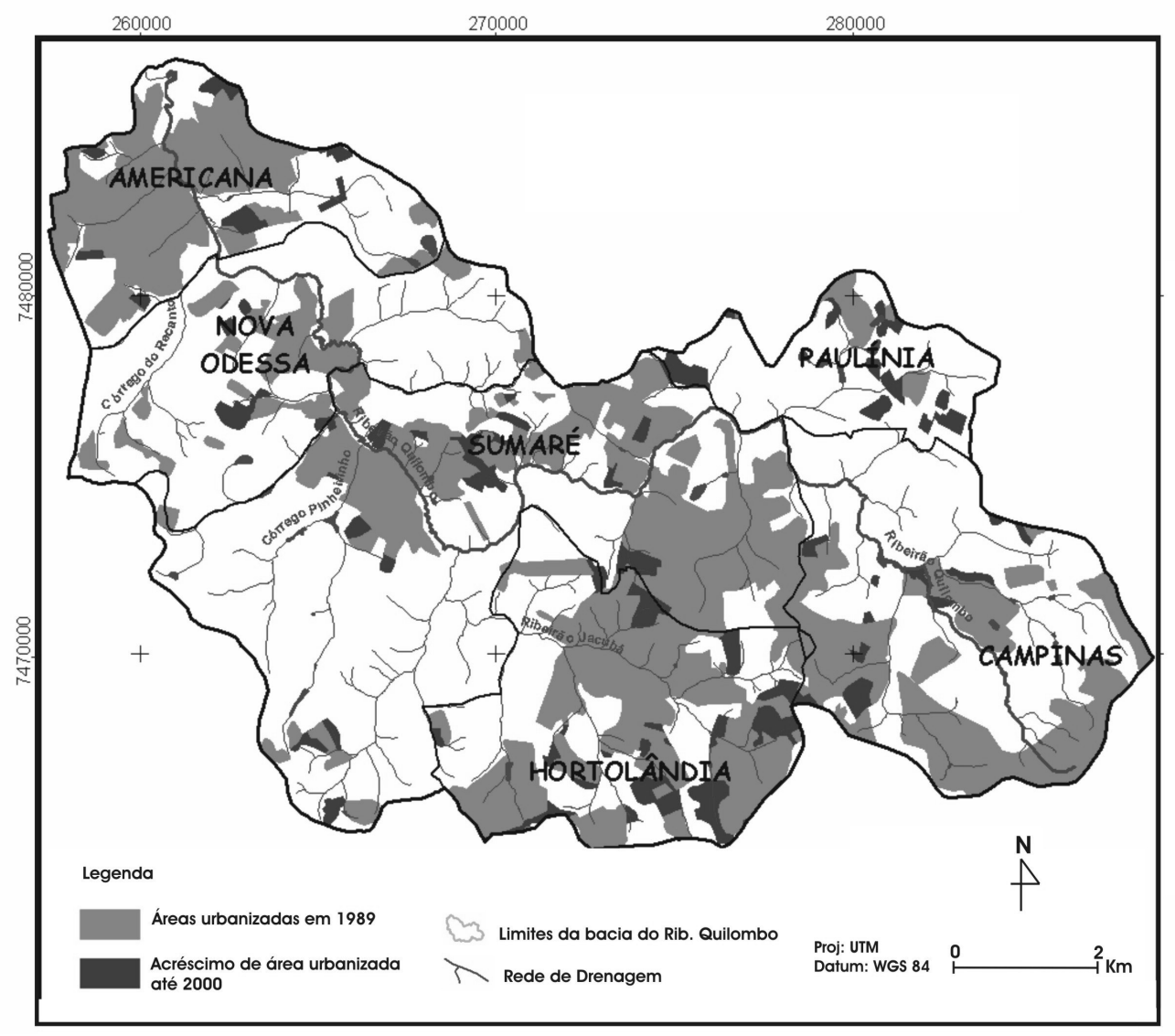

Figura 5 Crescimento das áreas urbanizadas nos municípios inseridos na bacia hidrográfica do Ribeirão Quilombo, período de 1989 a 2000 (adaptado de Pires e Santos, 2002). 
Tabela 4 Indicadores de qualidade de vida da população residente nas áreas urbanas de Campinas situadas na bacia do Quilombo

\begin{tabular}{|c|c|c|c|c|c|}
\hline Indicador & Variável & $\begin{array}{r}\text { Valor } \\
\text { por região* }\end{array}$ & $\begin{array}{r}\text { Média } \pm \\
\text { d.p.** }\end{array}$ & Mínimo*** & Máximo*** \\
\hline \multirow{2}{*}{ Grau de Ocupação } & Densidade demográfica (hab/ha) & 26,20 & $\begin{array}{r}91,76 \pm \\
72,67 \\
\end{array}$ & 1,14 & 430,47 \\
\hline & Densidade de domicílios (dom/ha) & 7,46 & $\begin{array}{r}25,71 \pm \\
20,55\end{array}$ & 0,30 & 146,11 \\
\hline $\begin{array}{l}\text { Condições de } \\
\text { Moradia }\end{array}$ & $\begin{array}{l}\text { Domicilios improvisados e/ou em } \\
\text { aglomerados sub-normais (\%) }\end{array}$ & 14,70 & $\begin{array}{r}31,81 \pm \\
77,26 \\
\end{array}$ & 0,00 & 100,00 \\
\hline \multirow{2}{*}{$\begin{array}{l}\text { Saneamento } \\
\text { Ambiental }\end{array}$} & Coleta domiciliar do lixo (\%) & 96,70 & $\begin{array}{r}97,61 \pm \\
9,70 \\
\end{array}$ & 42,63 & 100,00 \\
\hline & Esgoto coletado pela rede geral (\%) & 88,44 & $\begin{array}{r}81,56 \pm \\
34,10 \\
\end{array}$ & 0,00 & 100,00 \\
\hline \multirow{2}{*}{$\begin{array}{l}\text { Renda dos } \\
\text { Responsáveis }\end{array}$} & 0 a 2 salários mínimos (\%) & 29,14 & $\begin{array}{r}31,82 \pm \\
19,75\end{array}$ & 0,00 & 95,35 \\
\hline & 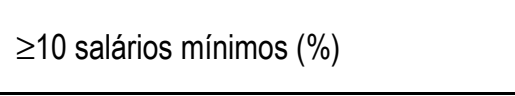 & 17,85 & $\begin{array}{r}16,85 \pm \\
21,81 \\
\end{array}$ & 0,00 & 83,41 \\
\hline \multirow{2}{*}{ Escolaridade } & $\begin{array}{l}\text { Não-alfabetizados maiores de } \\
5 \text { anos }(\%)\end{array}$ & 8,56 & $\begin{array}{r}9,62 \pm \\
7,04 \\
\end{array}$ & 0,60 & 31,34 \\
\hline & $\begin{array}{l}\text { Responsáveis que freqüentaram curso } \\
\text { superior (\%) }\end{array}$ & 12,96 & $\begin{array}{r}12,23 \pm \\
16,85\end{array}$ & 0,00 & 61,13 \\
\hline
\end{tabular}

Fonte: IBGE (2002)

* Obtido agregando-se os dados de todos os setores censitários urbanos

** Calculado a partir da análise isolada dos dados de cada setor censitário urbano

${ }^{* * *}$ Respectivamente, menor e maior valores encontrados a partir da análise isolada dos dados de cada setor censitário urbano

0 montante mais extremo registrado em 24 horas nos municípios banhados pelo Quilombo na série histórica entre 1960 e 1999 estão expressos na Tab. 5.

Tabela 5 Valor máximo de precipitação diária $(\mathrm{mm})$ nos municípios que compõem a Bacia do Quilombo (não há posto de coleta no município de Hortolândia)

\begin{tabular}{lcr}
\hline Município & Máximo em 24h & Data \\
\hline Americana & 143,3 & $16 / 01 / 1962$ \\
Campinas & 185,0 & $25 / 12 / 1997$ \\
Nova Odessa & 112,0 & $25 / 05 / 2005$ \\
Paulínia & 119,4 & $01 / 12 / 2003$ \\
Sumaré & 120,9 & $25 / 05 / 2005$ \\
\hline
\end{tabular}

Fonte: IAC e DAEE

A precipitação regional também é afetada pela atuação do evento El Niño, quando de grande intensidade. Em 1983, ano em que ocorreu um dos mais fortes fenômenos do século XX, os municípios estiveram sob chuvas intensas durante 10 dias consecutivos (29/05 a 07/06), e as águas do Ribeirão Quilombo invadiram diversas residências em Americana, Campinas, Paulínia, Nova Odessa, Hortolândia e Sumaré.

A área tem como agravante 0 aumento das chuvas intensas observado na região (VICENTE, 2005), que associado ao desordenado crescimento urbano deve acarretar um maior número de pessoas atingidas.

Não obstante os estudos realizados sobre os elementos climáticos e o conhecimento empírico existente sobre a dinâmica do clima regional, as informações do comportamento da precipitação no sítio ainda são insuficientes para a estruturação de medidas preventivas eficientes.

Foi possível através da correlação de dados georeferenciados da área de estudo, realizar uma primeira abordagem extraindo pesos e parâmetros a serem considerados em etapas 
posteriores no que concerne a sua participação no todo funcional da bacia e sua relação com episódios extremos de precipitação. A parametrização exposta na Tab. 6 constitui uma sumarização analítica que pode ser aplicada de maneira prática em operações que envolvem álgebra de mapas, ou mesmo norteando de forma qualitativa a otimização de parâmetros com maior peso, priorizando a melhoria de seu mapeamento em termos de escala e precisão.

Tabela 6 Parâmetros de mapeamento e análise da bacia do Ribeirão Quilombo. Adaptado de Vicente (2001)

\begin{tabular}{|c|c|c|c|c|}
\hline Parâmetro & Elemento & Variável & Atributos & Peso \\
\hline Hidrológico & Fluviosidade & Rede de drenagem & $\begin{array}{c}\text { Dimensão } \\
\text { Distribuição } \\
\text { Hierarquia } \\
\text { Vazão }\end{array}$ & $\begin{array}{l}2 \\
2 \\
2 \\
2\end{array}$ \\
\hline Geomorfológico & Relevo & Altimetria & $\begin{array}{c}\text { Clinografia } \\
\text { Hipsometria } \\
\text { MNT } \\
\text { MDS } \\
\text { MDE } \\
\end{array}$ & $\begin{array}{l}3 \\
4 \\
4 \\
4 \\
4\end{array}$ \\
\hline Uso e ocupação da terra & Ação antrópica & Localização/densidade & $\begin{array}{c}\text { Densidades: } \\
\text { populacional } \\
\text { habitacional } \\
\text { vegetação }\end{array}$ & $\begin{array}{l}4 \\
5 \\
3 \\
\end{array}$ \\
\hline Pedológico & Solos & $\begin{array}{l}\text { Localização } \\
\text { Classificação }\end{array}$ & $\begin{array}{c}\text { Granulometria } \\
\text { Textura }\end{array}$ & $\begin{array}{l}1 \\
1 \\
\end{array}$ \\
\hline Climatológico & Pluviosidade & Chuva & $\begin{array}{l}\text { Sazonalidade } \\
\text { Intensidade }\end{array}$ & $\begin{array}{l}4 \\
5\end{array}$ \\
\hline Meteorológico & Pluviosidade & Chuva & $\begin{array}{l}\text { Distribuição } \\
\text { Intensidade }\end{array}$ & $\begin{array}{l}4 \\
5\end{array}$ \\
\hline
\end{tabular}

Cabe reiterar que cada peso é um subproduto quantitativo e relativo, sendo que toda a parametrização proposta aqui é flexibilizada por seu próprio uso e aplicação contínua, sendo passivel, por representar um banco de dados geográfico (SIG), de ampliações, refinamentos, reduções, etc. Constitui, portanto, um cabedal qualitativo/quantitativo que auxilia os processos de mapeamento e análise de maneira geral.

Como exemplo tem-se o parâmetro pedológico, que por se tratar de uma área densamente urbanizada e de relevo suave, tem uma participação relativamente reduzida, dadas as propriedades que podem ser consideradas (granulometria e textura), que de fato encontram-se subjascentes a uma nova dinâmica de cobertura e uso da terra. Uma importância maior é atribuída para aspectos como nível de impermeabilização e relevo, os quais incidem diretamente no tempo de percolação da água, por exemplo. Dessa maneira melhores resultados devem ser alcançados mediante a otimização do mapeamento com a esses parâmetros, visto que, as propriedades dos solos, neste caso, participam de forma menos decisiva.

A realização de um estudo diagnóstico constitui-se, portanto, numa etapa essencial do entendimento da complexidade inerente a áreas densamente ocupadas. 0 delineamento de processos espaço-temporais físicos e antrópicos sob o contexto analítico dos recursos das geotecnologias, propicia tanto a otimização de correlações quanto a priorização do que deve ser mapeado com maior ou menor precisão, visto que se dispôe de uma realidade financeira pouco favorável a projetos de alto custo e pouca objetividade. 
PEREZ FILHO, A.; MATTOS, S.H.V.L.; ORSI, L.; VICENTE, A.K.; VICENTE, L.E. (2006) Traking and management of urban river basins associated to flood: diagnosis of the Ribeirão Quilombo river basin in Campinas Metropolitan Area using geotecnologies. Revista do Departamento de Geografia, n. 19, p. 44-54.

Abstract: Lack of data in appropriates spatial and temporal scales is a great obstacle to implantation of flood alert systems. The present article results of an exercise that aim to verify data currently available for Metropolitan Region of Campinas and, consequently, which ones would still be necessary to create a system of this type. Quilombo river basin was chosen as a pilot-area and a diagnosis of its physical and social-economical characteristics was made, taking pre-existing data and correlating then with SIG. The results obtained by this diagnosis indicate the necessity of a high-resolution mapping and of a broader and refined monitoring in comparison of those available at present. Based on correlations between spatial data, and objectifying to enhance precision of data collection in semi-detail scale, adequate points to install new fluvio and pluviometrical stations are proposed.

Keywords: Flooding; Risk management; Urban river basin; Geographic Information System; Metropolitan Region of Campinas.

Recebido em 15 de março de 2006, aceito em 17 de outubro de 2006.

\section{Referências}

BAENINGER, R. Região Metropolitana de Campinas: expansão e consolidação do urbano paulista. In: HOGAN, D.J. et al. Campinas: Unicamp, 2001.321-348.

ESALQ/USP < www.cena.usp.br/piracena> acessado em maio de 2005.

GONÇALVES, N. M. S. Impactos fluviais e desorganização do espaço urbano em Salvador. In: MONTEIRO, C. A. F.; MENDONÇA, F. (Org.) Clima Urbano. São Paulo: Contexto, $2003.192 \mathrm{p}$.

INSTITUTO BRASILEIRO DE GEOGRAFIA E ESTATÍSTICA (IBGE). Base de informações por setor censitário - Censo Demográfico 2000: Resultados do Universo. Campinas-SP (3509502). Rio de Janeiro: IBGE, 2002. (CD-Rom).

PIRES, M.C.S.; SANTOS, S.M.M. Evolução da mancha urbana. In: FONSECA, R.B.; DAVANZO, A.M.Q.; NEGREIROS, R.M.C. (org). Livro Verde: desafios para a gestão da Região Metropolitana de Campinas. Campinas: Unicamp, 2002. 498p.
TAVARES, A. C. O clima local de Campinas: introdução ao estudo do clima urbano. 1974. 186 p. Dissertação de mestrado em Geografia. Faculdade de Filosofia, Letras e Ciências Humanas, Universidade de São Paulo, São Paulo.

VICENTE, A. K. Eventos extremos de precipitação na Região Metropolitana de Campinas. 2005. 143p. Dissertação de mestrado em Geografia. Universidade Estadual de Campinas - UNICAMP. Campinas, São Paulo.

VICENTE, L. E. Geoprocessamento aplicado à gestão territorial: uma proposta de abordagem sistêmica para o meio urbano de Presidente Prudente. 2001. 110 p. Dissertação de mestrado em Geografia. Faculdade de Ciências e Tecnologia. Universidade Estadual Paulista - UNESP, Presidente Prudente - SP. 